\title{
Many Infectious Human Diseases Can be Arrested with Oxygen
}

\section{Delik D. Gabaev}

A. V. Zhirmunsky Institute of Marine Biology of the Far Eastern Branch of the Russia Academy of Science, Vladivostok, Russia

\author{
Email address: \\ gabaevdd@mail.ru
}

\section{To cite this article:}

Delik D. Gabaev. Many Infectious Human Diseases Can be Arrested with Oxygen. American Journal of Clinical and Experimental Medicine. Vol. 4, No. 6, 2016, pp. 201-203. doi: 10.11648/j.ajcem.20160406.17

Received: July 29, 2016; Accepted: October 29, 2016; Published: November 23, 2016

\begin{abstract}
Many bacteria and viruses that cause dangerous diseases for all living things, appeared on Earth when there was no oxygen on the planet. Therefore, they are anaerobe organisms. Atmospheric oxygen is baleful for them. In case of a disease, the oxygen delivery arrest the infection and cancer cells.
\end{abstract}

Keywords: Cancer and Other Diseases, Saturation by Oxygen

\section{Introduction}

According to the Yu. Odum's rule, in a food chain or a food web with the constant energy pathway, small organisms with high specific metabolism are the bigger biomass, than the larger ones. Remains of morphologically differentiated prokaryotes are found in the rocks aged more than 3.5 billion years [1], when the Earth had no oxygen, which may have been the reason for their anaerobicity. Therefore, atmospheric oxygen is baleful for them. They would have disappeared from the Earth, if it were not for the living beings, in which they are able to settle. The fact is, that due to their covers and energy, such living beings provide them for the protection from the external environment and provide them for the favorable anaerobic conditions. These conditions are so favorable and the bacteria's metabolism is so high that they and their metabolites cause the disease symptoms in a few days. However, in case the protection is damaged and the anaerobic organisms contact with the oxygen, they die and the human recovers.

\section{Treatment by Piercing of Covers}

Thus, such a widespread disease as diphtheria, which often caused children's death in the last century, is easily treated after the destruction of the diphtheric membrane formed in the oral pharyngeal cavity. One of the USSR leaders - Sergo Orjonikidze - employed this method: he pierced a swelling, which prevented him from breathing, with his finger and then quickly got healthy without any medication. Another disease is furunculosis caused mainly by facultative anaerobes Staphylococcus aureus, which settle in different parts of the body, including the faceis traditionally cured by deep exsection and the following protection with antiseptics [2]. However, the scars after the surgery remain for many years. In the second half of the last century, my mother told me about the traditional methods of treatment of explosive wens, which are successfully used by geologists in expeditions for stays in harsh environments. In case of explosive wens, geologists disinfect the explosive wen itself and the sewing needle; then they pierce the reddened skin in 3-4 locations around the head. No picking and squeezing are required. After piercing the skin and release of the ichor, the explosive wen resolves very quickly. After I left my parents and moved 10 thousand $\mathrm{km}$. away, I entered different climatic conditions and also began to find the explosive wens on my body around the head. After using the geologists' method, I quickly cured the disease. One day, as a result of supercooling in the sea during the dive, and of the stress in the fight with an octopus, I dreamt nightmares. In the morning, I found an explosive wen under my arm. Explosive wens usually cause soreness. However, after the timely measures it resolved the next day. The P. Basler, MD, recommends similar measures but he advises to make one puncture of the explosive wen head and to squeeze it then [3]. 


\section{Treatment by Saturation of Oxygen}

Staphylococcus aureus, settling in the lung tissue, may have even more negative impact on the person. It causes pyodermatitis, rhinitis, sinusitis, pharyngitis, laryngitis, bronchitis, pneumonia, which in the closed hospital environment affect a person more often than at home and cause oxygen starvation, leading in some cases to the most severe complications - sepsis. It is this bacterium, which often leads to the infection of blood and therefore is the most dangerous one [2]. The organism tries to increase the flow of oxygen itself to neutralize a toxic effect to cure this infection: hyperemia is formed due to a rush of blood to the site of inflammation, in these conditions the blood vessels dilate, and thevenous blood flow is reduced [4]. Sepsis caused by the staphylococcus can also be cured after placing the affected area of the body into a plastic insulator through which sterile air is purged [2], or enter an active carrier of oxygen - perftoranum [5].

Apparently, anaerobic bacteria are the originators of another infectious diseases - tuberculosis, because they die in the environment and are transferred only between humans. Even Ayurveda recommends the mounting air for healing. Mycobacteria avoid a good oxygenation and prefer to settle in the relatively poor oxygenated apical segments of the lung lobes. Improved oxygenation of the lungs observed in the intensification of breath in the thin air of mountain resorts contributes to inhibition of growth and reproduction of mycobacteria. In 1822, the English physician James Carson suggested the idea and made the first, however, unsuccessful attempt to treat the pulmonary tuberculosis with the artificial pneumothorax (introduction of air into the pleural cavity) [6]. After six decades, in 1882, the Italian Carlo Forlanini managed to introduce this method into practice. A. N. Rubel was the first in Russia who applied the artificial pneumothorax in 1910. Apparently, it was based on the stories of treatment of TBC patients who suffered chest injuries in battles or in duels. Nowadays, the hemotoxins, interferon gamma (IFN $\gamma$ ) and interleukin -2 (IL-2) activate the migration of macrophages in MTB (Mycobacterium tuberculosis) settlement direction and increase the enzyme activity and overall bactericidal activity of macrophages [2]. The activated macrophages produce the reactive oxygen and hydrogen peroxides intensely. This so-called "oxygen blast" affects the phagocytosed pathogens of tuberculosis[2].

Actinomycosis, diseased by the anaerobic bacteria Actinomyces israelli is difficult to treat due to the dense arrangement of tissues: therefore, recovery generally occurs after surgery by opening and removing the focus of infection [7]. Currently, the viruses are recognized as the ancient organisms that appeared, presumably, before the cell division into three domains of life [8], and we can assume that viruses are anaerobes and they can be killed with the atmospheric oxygen. The doctors treating the flu confirm this version as an example, Dr. Calvin Thrash advises the ill people to breathe fresh air [3].

One of the most dreaded human diseases - cancer - also appears frequently because of infection, both bacterial and viral [2]. The stomach cancer may develop in any compartment of the stomach and spread to other organs, especially the esophagus, lung and liver. Genetics is not the only factor responsible for the tumor initiation in the stomach. Other factors are dietary habits, infections and environmental factors [2]. For example, the risk of stomach cancer, when being infected with Helicobacter pylori infection, increases almost 4 times; moreover, $90 \%$ of patients with stomach cancer are infected with $H$. pylori, and this bacterium is present in half of the excised cancer tumours [9]. The atrophic gastritis is under a "cancer" suspicion, as the people infected with it are three times more likely to get cancer, whereas a decrease in production of hydrochloric acid allows the bacteria $H$. pylori to settle massively and permanently, creating ulcerative defects and tumors [9]. Other microorganisms such as streptococci, staphylococci, micrococci, Candida fungi etc. also colonize the gastric mucosa [2]. The tumor cells are carried with the blood stream to the liver and rarely to the lungs, where the different metastases appear.

In the developed countries, the lung cancer is the most common cancer and the most common cause of death from cancer. According to the data for the year 2000, the lung cancer caused the death of $32 \%$ of men and $7.2 \%$ of women who had any of malignancies found [10]. The main causes of any cancer include carcinogens (such as tobacco smoke), ionizing radiation and viral infection. Their effect causes the cumulative DNA changes in the lepidic tissue of the lung bronchi (bronchial epithelium): the more damaged the tissue is, the higher is the risk of cancer [11]. Viruses that can cause cancer include human papilloma virus [12], the JC virus [13], Simian Virus 40 (SV 40), BK virus and cytomegalovirus [14]. These viruses can influence the cell cycle and inhibit apoptosis, contributing to the uncontrolled cell division. The oxygen effect - radiation in the presence of $\mathrm{O}_{2}$ with the formation of peroxy radicals, amplifying effect of radiation - is used to cure the cancer together with the radiation therapy: the increased oxygen content in the tumor increases the radiation damage of tumor cells while minimizing damage to healthy tissues [15]. The Russian doctor Borisov uses similar methods [16]. He saturates the body with preparations containing chlorophyll, and then irradiates a person with the laser. Rapidly dividing cancer cells are saturated with chlorophyll more than others are and under the laser ray of a certain frequency the chlorophyll releases oxygen, which has a devastating effect on the cancer cells. By this method he restores immunity of the hopeless patients, who can be cured of the tumor in many parts of the body after these procedures. He uses the same technique to cure the viral hepatitis [16]. The US researchers of the University of Miami confirm the anaerobic nature of the infection causing cancer. Under the anaerobic conditions, the cancer cells degrade sugars by glycolysis, but adding the false sugars (in particular 2-DG) blocking the glucose to the patient's organism, provokes the starvation of the growing cancer cells: when this happens, the normal cells do not 
experience discomfort because oxygen is extracted from fats and proteins [17]. Other US researchers from the Cancer Institute in Maryland also confirm the therapeutic effect of oxygen. They found that sport and moderate physical exercises for 2.5 hours per week reduce the risk of cancer [18].

The Russian Journal of Healthy Lifestyle (HLS) contains notes of cancer cure with the help of the atmospheric oxygen: a cancer patient, who had the fourth stage of lung cancer began to run in the open air and first he fell from exhaustion after a few steps. However, he did not give up and continued to increase the excercise load and after a while he recovered from this terrible disease. Another cancer patient, who had the fourth stage of the gastric cancer, went into the woods and ate only forest products. After 40 days, he was very exhausted and barely made it home, but after he came back doctors discovered that he had no disease. In 1992 I worked as the diver on cropping of a sea urchins and often it was necessary to breathe hot air from an aqualung. It has led to drying of lungs and any insignificant overcooling put me to bed with heat. However after diving, attempts of spitting after exhalation, work on a personal of land parcel and amusements by the European football of weekly have improved my condition. And has finished my treatment of tempering by douche by cold water in the morning and in the evening and contrast douche after bath acceptance.

\section{Conclusion}

The given information suggests that atmospheric oxygen is the same poison for anaerobic infections as chemicals, but its effect does not have such a devastating impact on humans as the latter one, so one should try to make the most of its beneficial properties.

\section{References}

[1] E. P. Odum. Basic Ecology. Moskow: Mir. 328. 1986.

[2] https://www.ru.wikipedia.org

[3] The doctors book of home remedies. Thousands of tips and techniques anyone can use to heal everyday health problems (ed. Tkac D). Moskow: Publishing house of the Riderz Digest. 560. 2007.
[4] http://www.ayzdorov.ru

[5] http://www.faber-lic.ru

[6] W. Devitt. Indications for pneumothorax. Chest. 2. pp. 8-26. 1936.

[7] http://www.yfamily.ru

[8] W. J. Mahy, M. H. V. Van Regenmortel (eds). Desk Encyclopedia of General Virology. Oxford: Academic Press. 29. 2009.

[9] http://www.euroonko.ru

[10] V. A. Nidylin, B. V. Erdnieva. About epidemiology of the cancer of Lungs // Medical bulletin of Bachkorstan: a review. The Bashkir State of Medical University. Ufa. 4 (1). pp. 6671. 2009.

[11] A. A. Vaporciyan. Cancer Medicine. B C Decker. pp. 12271292. 2000

[12] C. Leroux, N. Girard, V. Cottin, et al., Jaagsiekte sheep Retro virus (JSRV): from virus to lungcancer in sheep // Veterinary Research. 38(2): 211-228. 2007.

[13] M. Palmarini, H. Fan. Retrovirus-induced ovine pulmonary adeocarcinoma, an animal model for lung cancer // $\mathrm{J}$ of the National Cancer Institute (Oxford Univesity Press). 93(21). pp. 1603-1614. 2001.

[14] Y. W. Cheng, H. L. Chiou, G. T. Sheu et al., The association of human papilloma virus 16/18 infection on with lung cancer among nonsmoking Taiwanese women // Cancer Research (American Association for Cancer Research). 61(7). pp. 27992803. 2001

[15] Z. Bak, P. Aleksander. Radio biology bases. Moskow: The Foreign Literature. 500. 1963.

[16] A. Nikonov. To stop a cancer // Story. 6(92). pp. 18-21. 2016.

[17] H. Liu, M. Kurtoglu, C. L. Leon-Annicchiarico, et al., Combining 2-depxy-D-glucose with fenofibrate leads to tumor cell death mediated by simultaneous induction of energy and ER stress // Oncotarget. 7(24). pp. 36461-36473. 2016.

[18] Cleaning the Air. Quit smoking to day. U.S. Department of Health and Human Services. National Institute of Health. National Cancer Institute. NIT Pabliching № 08-1647. 38. 2008. 